\title{
El territorio como categoría fundamental para el campo de la salud pública
}

\author{
Territory as an essential category in public health sciences
}

Elis Borde', Mauricio Torres-Tovar ${ }^{\mathbf{2}}$

RESUMO Este ensayo hace una aproximación conceptual a la categoría 'territorio', vinculándola como categoría de análisis fundamental en salud pública. Se hizo una revisión de fuentes academicas en donde la geografía, las ciencias sociales y la salud se interrelacionan para reconocer como se concibe el territorio dentro del campo de la salud. La primera parte del texto aborda el territorio como ámbito de expresión del bienestar y malestar de la sociedad a partir de tres casos de configuración territorial. En la segunda parte se propone una discusión sobre la influencia/el papel el territorio en el campo de la investigación salud pública; lo que permite concluir que en el territorio se dan los procesos de producción y reproducción social, que constituyen la base de la determinación social de la salud-enfermedad-muerte.

PALAVRAS-CHAVE Vulnerabilidad social. Salud pública. Inequidad social.

ABSTRACT This essay seeks to conceptually approach the category of 'territory', assuming it as an essential research category in public health sciences. The first part addresses the territory as a marker of wellbeing and ill-being of society in relation to three cases of territorial configuration: territories of extractivist accumulation; urban territories of sacrifice and territories of life. In the second part of the essay, territory is discussed as a research category in public health.

KEYWORDS Social vulnerability. Public health. Social inequity. 


\section{Introducción}

El territorio es el escenario fundamental donde transcurre la vida. En él se expresa la condición de existencia material de las sociedades, establecida por los procesos productivos y reproductivos que se dan en su interior (SÁNCHEZ; LEÓN, 2006) y consecuentemente es producción social y de sentido (JIMÉNEZ; NOVOA, 2014), que configura el bienestar y malestar de las poblaciones que los habitan. En este sentido, entender/abordar el concepto de territorio es fundamental para comprender las desigualdades en los procesos de saludenfermedad y muerte, es decir, las diferencias en las formas de enfermar y morir, en las formas de sufrir y en las posibilidades de bienestar (BREILH, 2010; CDSS, 2012).

El abordar entonces el territorio, demandaría una reorientación de la acción de la salud pública para actuar sobre la determinación social de los procesos salud-enfermedad y muerte, re-territorializando su intervención y superando su acción focalizada en la enfermedad y en el ajuste de los estilos de vida de los individuos.

Partiendo del reconocimiento de que los procesos de salud-enfermedad y muerte no pueden ser comprendidos al margen de las dinámicas histórico-territoriales que han venido configurando el territorio en la medida en que este expresa la correlación de fuerzas en la sociedad, siendo "lugar material donde se desarrollan las relaciones sociales y se emplaza la infraestructura necesaria para el proceso productivo" (JIMÉNEZ; NOVOA, 2014, P. 8) y a la vez, sujeto de la producción. El presente ensayo pretende hacer una aproximación conceptual a la categoría territorio, vinculándola como una categoría de análisis fundamental al campo de salud pública y en particular de la salud colectiva.

La aproximación teórica al concepto de territorio que proponemos en este ensayo, surge en medio de la búsqueda de herramientas y claves analíticas que permitan orientar la elaboración de respuestas a preguntas sobre las "posibilidades para la vida en un sistema social centrado en la búsqueda frenética de la ganancia”, estructuralmente malsano (BREILH, 2010, P. 19), marcado por una matriz energética inviable, un desgarramiento de los territorios por el extractivismo (MACHADO-ARÁOZ, 2012), y otros procesos que han venido definiendo la determinación social de los procesos saludenfermedad y muerte.

A partir de la idea de 'productividad espacial' de Milton Santos (1993), exploramos y problematizamos lo que se produce en el ejercicio de poder, que marca el régimen de acumulación y producción capitalista en la modernidad, observando no solamente lo que se destruye, sino la multiplicidad de relaciones, sujetos, subjetividades, territorios, territorialidades y resistencias que se producen.

\section{El territorio como ámbito de expre- sión del bienestar y malestar de la sociedad}

El concepto de territorio es polisémico y su comprensión depende, en gran medida, de la perspectiva desde la que se aborda, si es carácter global, regional o local; si es desde las capas hegemónicas o desde las capas subalternas, entre otras.

Históricamente la comprensión del territorio estuvo ligada a las guerras por el control de espacios físico, realizadas con el fin de disponer tanto de sus recursos naturales como humanos (GOMBRICH, 2004). El territorio se entendió entonces como escenario con características y límites geográficos, del cual había que apoderarse tanto por el ejercicio de la fuerza armada como por el ejercicio ideológico. Esta comprensión también marcó la colonización de Abya Yala, en la que se fue construyendo una comprensión del territorio útil al pensamiento e interés de los colonizadores europeos (PORTO-GONÇALVES, 2002), para lo cual la geografía se fue configurando como una disciplina funcional, que contribuyó a instalar una cartografía dominante y aplanar la realidad a partir de la imposición de una racionalidad 
fundamentalmente basada en categorías dicotómicas contrastando culturas 'civilizadas' - culturas 'bárbaras', 'centro' - 'periferia' y 'ser' y 'no-ser'. Estas dicotomías generaron condiciones epistemológicas y ontológicas para legitimar la instauración de una separación entre la naturaleza y el hombre y la diferenciación y jerarquización entre 'razas', lo que posibilitó la posterior explotación violenta de recursos naturales y de las poblaciones no-blancas (CORONIL, 1999). Más allá de una comprensión funcional del territorio, se consolidaron materialmente 'territorios de acumulación'.

Tal como señalan Jiménez y Novoa (2014, P. 81), la historia del capitalismo ha demostrado su profunda capacidad re-organizativa, con

el capital buscando desplegarse territorialmente tratando de aniquilar el espacio por e tiempo en busca de mayores niveles de beneficio, renta o interés, apoyado directa o indirectamente por el Estado y sus estrategias de intervención y reconfiguración espacial.

En América Latina, el despojo territorial, a través de desplazamiento forzado, reprimarización económica, extranjerización de las tierras y privatización de los bienes comunes, ha asumido un papel destacado en los procesos de producción y acumulación capitalista y, consecuentemente, en el ordenamiento social de las sociedades.

Refiriendo a las huellas que ha dejado el pasado y que sigue realizando el presente del extractivismo en América Latina, Horacio Machado-Aráoz (2012) habla de la

capacidad performativa que la violencia expropiatoria tiene y ejerce recíprocamente sobre los cuerpos y los territorios. Violencia performativa con la capacidad de diseñar territorios por y mediante la 'inversión', que por su parte produce territorios 'nuevos', configurados funcionalmente para ajustarse a los requerimientos del capital, es decir, para ser territorios eficientes, productivos, rentables, competitivos. (MACHADO-ARÁOZ, 2012, P. 58).
Igualmente, mediante procesos de resistencia que han centrado su lucha en la defensa del territorio, las comunidades han revalorizado el concepto y visibilizado la coexistencia de múltiples territorialidades. El territorio ha dejado de ser comprendido como la base 'natural' física del estado o espacio en donde la sociedad y sus relaciones de poder solamente existen. Por el contrario, comienza a ser considerado como espacio de expresión de procesos que implican una triada inseparable - territorio-territorialidadterritorialización (PORTO-GONÇALVES, 2012), que refleja una comprensión del territorio como producción social y describe como diferentes actores sociales se apropian, representan y dotan los territorios de sentido.

Desde esta perspectiva, principalmente marcada por autores como Foucault, Lefebvre, Soja, Santos y Harvey, se forjó un 'giro espacial' hacia los años 60-70, que permitió complementar los análisis sobre la configuración histórica de los procesos de dominación, explotación y marginalización en el marco de la modernidad capitalista y aproximarse a la comprensión de las expresiones diferenciadas de estos procesos en los diferentes territorios y, de acuerdo con la triada territorio-territorialidadterritorialización, hacer conciencia de los procesos de consolidación de determinados tipos de territorios y de territorialidades sobrepuestas y en disputa.

En esta lógica, se ha llamado a comprender el territorio a la luz de la configuración de nuevas territorialidades establecidas por el marco de la globalización, en tanto se organiza principalmente por las dinámicas económicas de las transnacionales, incluso desconfigurando los estados-nación y estableciendo un sistema-mundo modernocolonial (MIGNOLO, 2003); categoría que permite comprender de mejor manera cómo el capital busca convertir al planeta en un solo territorio de expoliación y explotación.

Se trata de una nueva forma de comprender el territorio y repensar lo geográfico en la vía que lo plantea Porto-Gonçalves (2002), de 
entender que el espacio está impregnado de historia, reconocer que el ser social es indisoluble al estar en él, que el territorio es más que un contenedor de recursos naturales y población, que entraña aspectos materiales y simbólicos, que en él ocurre la cooperación y el conflicto y que es el locus donde coexiste materialidad y cultura, que son el fundamento de la vida y que configuran el bienestar y el malestar de las poblaciones. En este sentido, cabe citar a Horacio Machado-Aráoz (2012), para quien no hay territorio sin sujeto político que lo constituya como tal, así como

no hay sujeto sin materialidad del cuerpo-individuo viviente, cuyo proceso de vida, a su vez, no puede prescindir de los flujos energéticos que lo atan a un determinado espacio geofísico biológico proveedor. (2012, P. 57).

De tal modo, hay un proceso mutuamente constitutivo y constituyente (territorio y espacio producto/productor)

entre los flujos energéticos que van de los cuerpos a los territorios en forma de trabajo, y que retorna de los territorios a los cuerpos en forma de alimentos. La vida misma emerge, por tanto, de estos flujos y procesos vitales que conectan unos cuerpos a ciertos territorios. (MACHADO-ARÁOZ, 2012, P. 57).

Como forma de evidenciar las configuraciones de bienestar y malestar en los territorios, se abordan a continuación tres expresiones territoriales distintas que a nuestro parecer pueden ilustrar lo propuesto: territorios de acumulación extractivista, territorios de sacrificio urbano y territorios de configuración de la vida.

\section{TERRITORIOS DE ACUMULACIÓN EXTRACTIVISTA}

América Latina ha estado sometida desde hace varios siglos a la colonialidad de las decisiones y las políticas que han ordenado su territorio, y luego por un orden capitalista, que ha satisfecho las necesidades del capital globalizado y de elites nacionales, utilizando para ello múltiples violencias para despojar de los territorios a sus habitantes originarios, base sobre la cual se han configurado los estados-nación latinoamericanos y se han liberado espacios estratégicos de acumulación y producción capitalista, provocando despojo, violencia, desplazamiento y destrucción del medio ambiente y de las bases de supervivencia, particularmente de comunidades indígenas, palenqueras y campesinas, pero en esencia de la humanidad entera.

En la actualidad, los proyectos de integración regional como el IIRSA (Iniciativa para la Integración de la Infraestructura Regional Suramericana) y sus grandes obras de infraestructura (vías, petroleras, hidroeléctricas, minería) (BETANCOURT SANTIAGO, 2015) y las operaciones (para)militares en el marco de conflictos armados, constituyen ejemplos dramáticos de estos procesos y han marcado el paso y la calidad de la consolidación de 'territorios de acumulación' en el continente, definiendo lo que Harvey denominó 'acumulación por desposesión', un 'nuevo' imperialismo, que consiste en el uso de métodos de acumulación originaria que mercantilizan ámbitos, hasta entonces cerrados al mercado, para absorber la sobreacumulación de un determinado sistema territorial (excedente de trabajo y de capital) (HARVEY, 2005).

El extractivismo ha asumido un papel particularmente destacado en esta configuración y ejemplifica la triada territorio-territorialidad-territorialización que fundamentalmente define las características y posibilidades de vida, salud y bienestar en determinados territorios. Donde la exportación de productos primarios pasó a ser la clave de la nueva-vieja ecuación macroeconómica de la región, como indican los datos de la Comissão Econômica para a América Latina (Cepal) (2010) y como es discutido por Machado-Aráoz (2012, p. 54), 
El extractivismo avanza a un ritmo frenético, al compás del renovado auge de las explotaciones petroleras y mineras, con la expansión de la superficie territorial ocupada por monocultivos forestales, forrajeros y del agronegocio en general [...] bienes generados y localizados en determinados ecosistemas - el agua, el suelo, el aire, la energía, la biodiversidad - que son apropiados privadamente y desterritorializados para abastecer dinámicas 'económicas' localizadas en otros territorios.

Considera este autor que el extractivismo provoca un literal desgarramiento de los territorios, una expropiación ecológica y de la vida, es decir, de los 'recursos' que nos hacen 'cuerpos', por lo que habla de una expropiación 'eco-biopolítica' (MACHADO-ARÁOZ, 2012).

Las huellas que este tipo de economía deja sobre los territorios son evidentes en las deforestaciones, en las contaminaciones de ríos, lagos y suelos, en la pérdida de biodiversidad y bases de supervivencia, así como en las poblaciones en condición de discapacidad, enfermadas y muertas por contaminantes, como lo documenta el dossier de agrotóxicos de la Asociación Brasileña de Salud Colectiva (Abrasco, 2016), expresiones de los "costos sacrificiales del desarrollo" (MACHADO-ARÁOZ, 2012, P. 55), efecto de una marca constitutiva del modelo de desarrollo capitalista moderno/colonial: el sacrificio, que es ilustrativo de la insustentabilidad del modelo que se ha materializado en este tipo de territorios y han configurado 'zonas de sacrificio' ambiental.

Ante el avance del extractivismo en el continente, han proliferado las zonas de sacrificio y aumentado el número de sujetos sacrificados que, en áreas rurales de América Latina, son predominantemente poblaciones campesindias, no-blancas, de clases sociales bajas, construidos como 'otros' y, a pesar de su número, clasificados como 'minorías' (CORONIL, 1999).

Los territorios de acumulación extractivista, que son la punta de lanza del actual modelo de acumulación capitalista en regiones ricas en recursos primarios, como América Latina, configuran territorios de malestar, donde se arrasan ecosistemas y se destruye la vitalidad de los cuerpos.

\section{TERRITORIOS URBANOS DE SACRIFICIO}

Las territorializaciones del modelo de desarrollo dominante en el ámbito rural y la consolidación del territorio urbano están íntimamente relacionadas y evidencien otras dimensiones de procesos que configuran el bienestar y malestar que viven las poblaciones que habitan los respectivos territorios. El ejemplo acerca de los territorios urbanos de sacrificio, que se aborda en este apartado, se ve orientado por la comprensión de la urbanización establecida por Lefebvre (2000), según la cual se avanzó hacia un patrón de urbanización global donde la distinción entre lo rural y urbano se diluye, donde el campesinado queda subordinado a la industrialización de la agricultura y es sometido por las formas de vida urbanas.

En el escenario urbano se evidencian las grandes contradicciones del modelo de desarrollo capitalista y se materializan los procesos de dominación, explotación y marginalización en la organización espacial de las ciudades y en la materialidad de los guetos, banlieues, favelas y villas de miseria.

El malestar de la sociedad se refleja de forma particularmente violenta en la segregación territorial urbana y en las 'zonas de sacrificio' ambiental y social - un término adoptado por Marcelo Firpo-Porto (2013), que refiere a zonas que son expresión de la insustentabilidad de dicho modelo hegemónico de ciudad y desarrollo y se caracterizan por la contaminación industrial del aire, del agua y del suelo, pero también refieren a zonas de sacrificio social donde se niegan los derechos fundamentales y se ejerce violencia para adecuar los espacios a las necesidades de grandes emprendimientos y de los grupos sociales históricamente privilegiados. 
En América Latina los procesos que forjaron la urbanización acelerada cobran particular relevancia principalmente porque reforzaron la propagación de una producción espacial fragmentada, insustentable e inherentemente incompatible con el bienestar y la salud en las ciudades y marcan las desigualdades en los procesos salud- enfermedad y de la muerte en ciudades latinoamericanas (FIRPO-PORTO, 2013).

Las ciudades latinoamericanas y el territorio urbano se configuraron en relación a la imposición de territorialidades tanto en el campo, provocando o intensificando (el ritmo de) las migraciones hacia las ciudades, como en las ciudades, ambos respondiendo a ordenamientos territoriales modernodesarrollistas (BETANCOURT SANTIAGO, 2015), funcionales a la respectiva inserción estratégica de las ciudades en el sistema-mundo capitalista moderno/colonial, con el espacio local pasando a "ser un vector más de la 'economía-mundo"” (MACHADO-ARÁOZ, 2012, P. 59).

Estas ciudades-globales, o territorios nacionales convertidos en "espacios nacionales de la economía internacional" (SANTOS, 1993, P. 71), se caracterizan por ser espacios extremamente segregados, cuya organización espacial expresa, de una forma particularmente clara y violenta, las inequidades que estructuran el régimen de acumulación y producción capitalista, en las que la mayoría de la población vive en territorios malsanos y es sujeta a procesos incompatibles con una vida saludable y digna, incluyendo la violencia armada y la falta de saneamiento básico.

La insustentabilidad de este modelo de ciudad y de implícito/consecuente desarrollo capitalista se expresa en la necesidad de cada vez más 'sacrificios', presentados como 'costos inevitables del progreso'. Para la reducción de los impactos se proponen tecnologías e innovaciones urbanas, que de todas formas no logran parar la proliferación de 'zonas de sacrificio' ambiental, ni tampoco de 'zonas de sacrificio' social, en las que en nombre del 'orden', de la seguridad de algunos pocos y del 'progreso', sistemáticamente se niegan derechos fundamentales, se ejerce violencia y se produce muerte para poder adecuar los espacios para el capital.

Políticas públicas articuladas a los planes de ordenamiento territorial y a los planes de desarrollo de las ciudades, han asumido un papel decisivo en estos procesos y han posibilitado la consolidación de una producción espacial de las ciudades funcionales a la acumulación acelerada del capital. En las ciudades latinoamericanas esto particularmente se dio en el contexto de mega eventos o en el marco de campañas contra aparentes urgencias sociales como, por ejemplo, la 'guerra contras las drogas', que construyen un 'estado de excepción' en el sentido dado por Agamben (2004), instaurando un 'desorden estratégico' o, en palabras de Naomi Klein, un 'shock' y una

guerra civil legal, que permite la eliminación física no sólo de los adversarios políticos sino de categorías enteras de ciudadanos que por cualquier razón resultan no integrables en el sistema político. (AGAMBEN, 2004, P. 25),

liberando espacios estratégicos de acumulación y legitimando la consolidación de 'zonas de sacrificio'.

En las ciudades latinoamericanas, para gran parte de la población, el sufrimiento y la muerte son omnipresentes y definen lo que el filósofo puertorriqueño Nelson Maldonado-Torres (2007) ha denominado la 'diferencia sub-ontológica' que marca los 'sujetos socio-históricos que enferman' y cuya vida se desarrolla en territorios históricamente 'sacrificados'. Se producen en este sentido 'cuerpos jóvenes muertos' por tiros de fuerzas públicas o por la violencia más camuflada que se expresa en la segregación territorial y consecuentemente en la concentración territorial de miseria, marginalización y exclusión. En este sentido es importante retomar Antón y Damiano (2010) quienes señalan que 
la muerte de un cuerpo no es solamente el detenimiento del funcionamiento de un organismo biológico o, mejor dicho, este detenimiento arrastra consigo al conjunto de relaciones sociales que él viabilizaba. (ANTÓN; DAMIANO, 2010, P. 24).

Por otro lado, se producen cuerpos cansados, estresados, dependientes y esencialmente malsanos, que se juntan en sistemas de transporte crónicamente colapsados, se sedan con placebos altamente lucrativos para la industria farmacéutica y se engordan con productos industrializados. El 'cuerpo gordo’ es espacio de expresión de un malestar anclado en el consumismo, la aceleración de los ritmos de vida y la perdida de habilidades básicas para la supervivencia, como la cocina. En palabras de Gustavo Antón y Franco Damiano (2010):

Los cuerpos se transforman en este sentido en un indicador, en la expresión viva de procesos de enfrentamiento social. [...] A su vez captan las acciones de disconformidad como expresión de la lucha por recuperar porciones del propio cuerpo pero no en sentido abstracto, sino en los términos de recuperar la posibilidad de hacer ciertas acciones y de relacionarnos de determinados modos, dejando de lado otras formas posibles. (ANTÓN; DAMIANO, 2010, P. 12).

Las zonas de sacrificio son expresiones particularmente drásticas de cómo los territorios reflejan el malestar de la sociedad y cómo determinadas territorialidades configuran territorios malsanos, territorios en los que se reproduce y potencia el malestar de la sociedad: espacios cerrados y sistemáticamente violentados que concentran los marginalizados, excluidos, dominados, 'condenados de la tierra' (FANON, 1999).

\section{TERRITORIOS DE CONFIGURACIÓN DE LA VIDA}

Tal como lo plantea Porto Gonçalves (2012), las luchas extremadamente importantes en nuestra América latina, son luchas territoriales. Dentro de un territorio nacional existen múltiples territorialidades; el concepto de territorio fue desnaturalizado en el momento mismo de la conquista y colonización y sobre todo en la conformación de los estados nacionales. Fue un proceso de disputa por el control del espacio y fue un proceso de despojo para cientos y miles de pueblos, etnias, religiones, lenguas, naturale$\mathrm{za}$, riquezas y de vidas.

En el territorio consecuentemente se evidencian y configuran no solamente procesos destructivos de la vida sino también son escenarios base de las resistencias, talvez hoy las más potentes (ZIBECHI, 2003). Esto ha llevado a una lucha permanente en el continente, en donde principalmente los pueblos originarios y los campesinos han venido sentando una posición estableciendo que su lucha por el territorio no es solo de carácter político, sino también de orden cultural, social y epistémico, con lo cual cuestionan la colonialidad del poder, del saber, del conocer, del ser y del hacer. Desde esas dinámicas socio-políticas se ha venido construyendo una nueva mirada del territorio que conecta la tierra, la pacha mama, con las dinámicas esenciales de la vida.

Desde las resistencias y luchas de los subalternos; desde la búsqueda por de-colonizar pensamiento y acción; desde la construcción desde abajo, es decir desde la defensa y gestación de los territorios, se propone una nueva forma de entender y vivir los territorios, que busca de reconocer y establecer otras territorialidades, un mundo donde quepan muchos mundos (PORTO-GONÇALVES, 2002). Lo cual será posible si se rompe con el pensamiento de dependencia colonial y se generan otras matrices de racionalidad, para lo cual se hace necesario disputar el escenario epistémico y forjar procesos de re-territorialización para posicionar las formas propias de producir conocimiento y de realizar la vida que se tienen en el continente. 
Es el territorio como condición de existencia material y como espacio geográfico donde obtenemos los servicios ambientales que nos brinda la naturaleza; es comprender que en él se dan los procesos de apropiación entendidos como territorialización y re-territorizalición (PORTO-GONÇALVES, 2002). Es concebir entonces el territorio en clave de materialidad, simbolismo, apropiación y construcción de identidad, en una simbiosis territorio - cultura - identidad (ESCOBAR, 2010), lo que lleva a la generación de múltiples y diversos territorios, en contraposición a la visión colonial homogenizante de los territorios, que los ve como escenario exclusivo de explotación y expoliación.

Ese es el sentido del territorio, entendido más que como simple tierra, escenario donde acontece la vida, lugar donde puede transcurrir la existencia con dignidad. Como lo expresa Arturo Escobar (2010, P. 40)

cualquier territorio es un territorio de la diferencia en tanto implica una formación ecológica, cultural y socialmente única de lugar y de región [...] lo que está envuelto [...] [en las disputas territoriales] [...] es la comprensión y defensa de la vida en sí misma, en todas sus complejas manifestaciones [...] [Por esto], el punto para los movimientos [...] no es sólo el 'ambiente' sino el hecho de ser diferente $y$, en última instancia, la vida en sí misma; de ahí que los territorios de la diferencia también son los territorios de vida, en la conceptualización de los activistas.

Es decir, el territorio produce social y biológicamente la vida, indefectiblemente ligada con la salud. Esto lo saben muy bien las comunidades y por esto han construido una episteme que liga territorio con vida y por eso lo defienden con arraigo, valentía y terquedad.

\section{EL TERRITORIO EN LA SALUD PÚBLICA}

La aproximación al territorio desde la salud pública ha sido marcada por tres grandes tendencias. Tradicionalmente, la categoría de territorio se ha utilizado para geográficamente delimitar áreas o referir a divisiones administrativas en conjunto con una comprensión 'geométrica' del espacio (MONKEN ET AL., 2010). Por otro lado, la aproximación se ha dado por el interés de relacionar el contexto social, comunitario y las características de ecosistemas a los procesos salud-enfermedad y muerte y se ha articulado en torno de la discusión sobre 'entornos', 'contextos', 'escenarios' y 'determinantes sociales de la salud', que si bien ha podido avanzar en la comprensión de la configuración social de las desigualdades en salud, continúa disociando los procesos biológicos de los procesos sociales, reduciendo las relaciones a un nexo externo (BORDE; HERNÁNDEZ; FIRPO-PORTO, 2015), desarticulado de las dinámicas territoriales.

$Y$ en el marco de la emergencia de la Medicina Social y Salud Colectiva Latinoamericana, liderada por Breilh, Granda, Almeida-Filho y Laurell (BREILH, 2003; LAURELL, 1994; ALMEIDA-FILHO, 2000) entre otros, $\mathrm{y}$ aproximaciones posteriores principalmente por investigadores brasileros (SABROZA, 1991; BARRETO, 1998; MONKEN ET AL., 2010; FIRPO-PORTO; PACHECO; LEROY, 2013), se fueron consolidando abordajes más complejos, inspirados en la geografía crítica. Desde la Medicina Social y Salud Colectiva Latinoamericana se ha propuesto un marco de análisis enfocado en la 'determinación social de las desigualdades en los procesos salud-enfermedad y muerte', resaltando cómo enfermamos y morimos de forma diferenciada por una serie de determinaciones sociales: jerarquías sociales que definen el acceso y la calidad de los servicios de salud, la cantidad y el grado de violencia, las condiciones de vida y otros procesos que inciden sobre el proceso salud-enfermedad y muerte (prematura, sufrida, violentamente impuesta, entre otros). Particularmente Jaime Breilh (2003) y Maria Fernanda Solíz Torres (2016) han avanzado en la discusión acerca de las manifestaciones del proceso de determinación social, comprendido como el 
devenir socio-biológico-histórico-territorial de la salud-enfermedad, en los genotipos $\mathrm{y}$ en los fenotipos y en este sentido se han aproximado a lo que 'produce' el territorio y el orden social en términos de cuerpos y subjetividades. De tal manera, se han buscado formas para comprender la 'enfermedad' más que como un desequilibrio bioquímico, como expresión íntima de procesos histórico-sociales-espaciales en 'sujetos socio-históricos que enferman’ (HERNÁNDEZ; QUEVEDO, 1992).

No obstante, y a pesar de que el desarrollo acerca de la categoría de 'espacio' haya sido mayor (MONKEN ET AL., 2010), no se ha profundizado la dimensión territorial de los procesos de determinación social de la salud, talvez debido al sesgo historicista que marca las ciencias sociales y sus aplicaciones en el campo de la salud pública y en la salud colectiva, que ha llevado a la invisibilización de la dimensión espacio-territorial en la caracterización del patrón de poder de la modernidad capitalista y sus mecanismos de reproducción social.

El territorio conecta con la salud y la vida, en tanto en él se dan los procesos de producción y reproducción social, que son la base de la determinación social. Es en el espacio territorial donde se dan las relaciones entre los procesos naturales y los procesos sociales, denominado como metabolismo sociedad-naturaleza (BREILH, 2003). Dicho de manera más sencilla: la gente vive, enferma y muere dependiendo de las condiciones en que trabaja (producción) y vive (reproducción), dinámicas que se dan ligadas al territorio. Por lo tanto, la aproximación entre territorio y salud va más allá de la mera distribución espacial o de las características ambientales físicas que inciden en los perfiles epidemiológicos de los colectivos (SAMAJA, 2003).

El territorio se vuelve entonces un elemento que contribuye a comprender las complejas relaciones que se dan entre individuos, sociedad y naturaleza que dan cuenta de un determinado perfil de deterioro o de protección de las poblaciones que lo habitan
(SÁNCHEZ; LEÓN, 2006). En el territorio entonces están las claves para entender cómo se da la dinámica de producción de la vida y de la salud, y de él también emergen epistemes y praxis que pueden darle sostén a la vida en todos sus órdenes y complejidades.

Esta perspectiva le demanda al campo de la salud pública considerar al territorio como una categoría central, en tanto en él están las dinámicas poblacionales y las determinaciones que producen bienestar o deterioro a/en los colectivos. Y de otro lado, implica para el campo de la salud pública necesariamente conectar con otros campos de conocimiento para entender la complejidad territorial y a su vez, no despreciar e incorporar los conocimientos y las praxis de las propias comunidades, que han demostrado que saben conservar y potenciar la vida y la salud.

\section{Conclusiones}

Concluimos que en tanto en el territorio se dan los procesos de producción y reproducción social junto al metabolismo sociedad-naturaleza, son estos procesos los que constituyen la base de la determinación social que establece los perfiles salud-enfermedad-muerte de las poblaciones que lo habitan. Arriesgamos a sostener que el territorio es el escenario estratégico de disputa entre una visión que lo ubica como fuente de acumulación y por lo cual intensifica sus procesos de expoliación y explotación, contra una visión que lo ubica como el escenario donde se gesta la vida y su sustentabilidad.

El territorio no es solamente un entorno caracterizado por su geografía física, el paisaje y los elementos bióticos y abióticos de la naturaleza presentes en él. Es un escenario que se construye a partir de las relaciones históricas, sociales, culturales, económicas, políticas y ambientales, configurando el escenario donde pulsa la vida, la salud, la enfermedad y la muerte y donde se expresa las contradicciones y los conflictos 
producto de las relaciones de confrontación entre el poder hegemónico de las elites y las resistencias de los sectores subalternos, en la contienda por el control territorial.

Los costos sacrificares del 'desarrollo' dejan sus huellas sobre los territorios y los cuerpos (MACHADO-ARÁOZ, 2012), que se vuelven espacios de expresión del malestar de la sociedad en diferentes escalas, pero también espacios a partir de los cuáles se articulan resistencias.

Así como las 'zonas de sacrificio' y las enfermedades son expresiones concretas de este malestar, en tales espacios se evidencian la incompatibilidad del régimen de acumulación y producción capitalista con modos de vivir y espacios de vida digna, conquistados a partir de procesos de re-territorialización. Tanto el cuerpo como el territorio permiten 'diagnosticar' y documentar el nivel de destrucción y contradicción que conlleva la manutención de este modelo de desarrollo $\mathrm{y}$ ofrecen evidencias palpables que deben llevarnos a seriamente interrogarnos sobre los horizontes de sentido y consecuentemente los horizontes de transformación, que deben llevar a preguntarse al campo de la salud pública: ¿̇A dónde vamos? ¿Qué más y a quiénes más vamos a dejar sacrificar?

También es un llamado a desnaturalizar y problematizar quienes son 'sacrificados' para mantener el funcionamiento del modelo de desarrollo dominante y, de acuerdo con Frantz Fanon, sobre quienes 'son' y 'no-son' en esta sociedad.

El metabolismo sociedad-naturaleza que se expresa en lo territorial, configura la base de la determinación social del proceso saludenfermedad y muerte. Esto revela al campo de la salud pública la necesidad de apropiar la categoría de territorio como elemento sustancial para entender y explicar las dinámicas de la vida y de la salud, y la necesidad de articularse con otras disciplinas, con el saber y praxis de las comunidades, para comprender de manera integral el territorio, todo con la finalidad de potenciar la vida, en contraposición a los proyectos de expoliación y muerte que se les pretende imponer.

Producto del accionar de los movimientos sociales, particularmente en América Latina, que confrontan la colonialidad desde una perspectiva de de-colonialidad y de autonomía, el territorio viene ganando gran importancia siendo espacio y medio de recuperación de epistemes y praxis, así como fundamento para preservar y potenciar la vida en todas sus expresiones y complejidades.

Sostenemos entonces que el campo de la salud pública es un campo para potenciar la vida y no para contener la enfermedad y la muerte. Acogemos el territorio, no porque se coloque como un asunto de moda hoy en las reflexiones académicas, sino porque lo consideramos categoría central, que puede orientar la dirección del campo de la salud pública, brindando herramientas y claves analíticas que permitan orientar transformaciones estructurales a favor de la vida y bienestar de las sociedades y en contra del proyecto de despojo y muerte que se impone hoy.

\section{Colaboradores}

Elis Borde y Mauricio Torres-Tovar contribuyeron substancialmente a la concepción y elaboración del manuscrito. 


\section{Referências}

AGAMBEN, G. El Estado de excepción. Archipiélago: Cuadernos de Crítica de la Cultura, La Rioja, España, v. 60, p. 99-109, 2004.

ALMEIDA-FILHO, N. La ciencia tímida: ensayos de deconstrucción de la epidemiología. Buenos Aires: Lugar Editorial, 2000.

ANTÓN, G.; DAMIANO, F. El Malestar de los cuerpos. In: MARÍN, J. C. et al. (Org.). El cuerpo, territorio del poder. Buenos Aires: Ediciones Picaso, 2010. p. 19-38.

ARRIGHI, G. O longo século XX: dinheiro, poder e as origens de nosso tempo. Rio de Janeiro: Contraponto, 1996.

BARRETO, M. Ambiente e saúde: saúde e ambiente no processo de desenvolvimento. Ciência \& Saúde Coletiva, Rio de Janeiro, v. 3, n. 2, p. 21-22, 1998.

BETANCOURT SANTIAGO, M. Adecuaciones espaciales para la dominación: Conflictos moderno-coloniales en la Amazonia Andina bajo el avance de la integración y desarrollo via IIRSA. Tesis (Doctoral). Universidade Federal Fluminense, Niterói, 2015.

BORDE, E.; HERNÁNDEZ, M.; FIRPO-PORTO, M. Uma análise crítica da abordagem dos Determinantes Sociais da Saúde a partir da medicina social e saúde coletiva latino-americana. Saúde em Debate, Rio de Janeiro, v. 39, n. 106, p. 841-854, 2015. Disponible en: <http://www.scielo.br/pdf/sdeb/v39n106/0103-1104sdeb-39-106-00841.pdf>. Acceso en: 5 jul. 2016.

BREILH, J. Epidemiología crítica: ciencia emancipadora e interculturalidad. Buenos Aires: Lugar Editorial, 2003.

BREILH, J. Informe alternativo sobre la salud en América Latina. Quito: Global Health Watch, 2010.

CARNEIRO, F. F. et al. (Org.). Dossiê ABRASCO: um alerta sobre os impactos dos agrotóxicos na saúde. São Paulo: Expressão Popular, 2014.
COMISIÓN DE DETERMINANTES SOCIALES DE LA SALUD (CDSS). Subsanar las desigualdades en una generación. Alcanzar la equidad sanitaria actuando sobre los determinantes sociales de la salud. Ginebra: OMS, 2012.

\section{COMISSÃO ECONÔMICA PARA A AMÉRICA} LATINA (CEPAL). Estudio económico em América Latina y el Caribe: 2009-2010. Santiago de Chile: Naciones Unidas, 2010

CORONIL, F. Más allá del occidentalismo: hacia categorías geohistóricas no imperiales. Revista Casa de las Américas, Cuba, v. 39, n. 214, p. 21-49, 1999.

ESCOBAR, A. Territorios de diferencia: lugar, movimientos, vidas, redes. Popayán: Envión, 2010.

FANON, F. Los condenados de la tierra. Nafarroa: Txalaparta, 1999.

FIRPO-PORTO, M. Injustiça ambiental no campo e nas cidades: do agronegocio químico-dependente às zonas de sacrificio urbanas. In: FIRPO-PORTO, M.; PACHECO, T.; LEROY, J. P. Injustiça ambiental e saúde no Brasil: mapa de conflitos. Rio de Janeiro: Fiocruz, 2013, p. 133-174.

FIRPO-PORTO, M.; PACHECO, T.; LEROY, J. P. Injustiça ambiental e saúde no Brasil: mapa de conflitos. Rio de Janeiro: Fiocruz, 2013.

GOMBRICH, E. Breve historia del mundo. Barcelona: Planeta, 2004

HARVEY, D. Sobre reajustes espacio-temporales y acumulación mediante desposesión. Herramienta, [s. 1.], v. 29 , p. $7-21,2005$

HERNÁNDEZ, M.; QUEVEDO, E. Historia, ciencias sociales y educación médica. Educacion Medica y Salud, [s. 1.], v. 26, n.1, p. 35-50, 1992. Disponible en: <http:// hist.library.paho.org/Spanish/EMS/10433.pdf > . Acceso en: 5 jul. 2016. 
JIMÉNEZ, C.; NOVOA, E. Producción social del espacio: el capital y las luchas sociales en la disputa territorial. Bogotá: Ediciones Desde Abajo, 2014.

LAURELL, A. C. Sobre la concepción biológica y social del proceso salud-enfermedad. In: RODRÍGUEZ, M. I. Lo biológico y lo social: su articulación en la formación del personal de salud. Washington: OPS, 1994.

LEFEBVRE, H. La prodution de l'espace. París: Anthropos, 2000.

MACHADO-ARÁOZ, H. Los dolores de Nuestra América y la condición neocolonial. Extractivismo y biopolítica de la expropiación. Observatorio Social de América Latina, Buenos Aires, n. 32, sep. 2012.

\section{MALDONADO-TORRES, N. Sobre la colonialidad} del ser: contribuciones al desarrollo de un concepto. In: GROSFOGUEL, R.; CASTRO-GÓMEZ, S. El giro decolonial: reflexiones para una diversidad epistémica más allá del capitalismo global. 1. ed. Bogotá: Siglo del Hombre, 2007. p. 127-167.

MIGNOLO, W. Historias Locales / Proyectos Globales: Colonialidad, conocimientos subalternos y pensamiento fronterizo. Madrid: Akal, 2003.

MONKEN, M. et al. O território na saúde: construindo referências para análises em saúde e ambiente. In: MIRANDA, A. C. et al. (Org.). Território, Ambiente e Saúde. Rio de Janeiro: Fiocruz, 2008. p. 23-41.

PORTO-GONÇALVES, C. W. Da Geografía às Geografias: um mundo em busca de novas territorialidades.
In: CECEÑA, A. E.; SADER, E. (Org.). La guerra infinita: hegemonía y terror mundial. Buenos Aires: Clacso, 2002, p. 217-256.

SABROZA, P. Espaço e produção de endemias. In: ALAMES. Taller de la Asociación Latinoamericana de Medicina Social. Caracas: Alames, 1991.

SAMAJA, J. Desafíos a la epidemiología: pasos para una epidemiología Miltoniana. Revista Brasileira de Epidemiologia, São Paulo, v. 6, n. 2, p.105-120, 2003.

SÁNCHEZ F. V.; LEÓN, N. Territorio y salud: una mirada para Bogotá. In: JIMÉNEZ, L. C. (Org.). Región, espacio y territorio en Colombia. Bogotá: Universidad Nacional de Colombia, 2006.

SANTOS, M. Los espacios de la globalización. Anales de geografía de la Universidad Complutense, Madrid, n. 13, p. 69-77, 1993. Disponible en: <https:// revistas.ucm.es/index.php/AGUC/article/viewFile/ AGUC9393110069A/31671>. Acceso en: 5 jul. 2016.

SOLIZ TORRES, M. F. Salud colectiva y ecología política: la basura en Ecuador. Quito: Universidad Andina Simón Bolívar, Ediciones La Tierra, 2016.

ZIBECHI, R. Los movimientos sociales latinoamericanos: tendencias y desafíos. Observatorio Social de América Latina, Buenos Aires, n. 9, p. 185-188, 2003.

Recebido para publicación en agosto de 2016

Versión final en noviembre de 2016

Conflicto de intereses: inexistente

Apoyo financiero: no hubo 